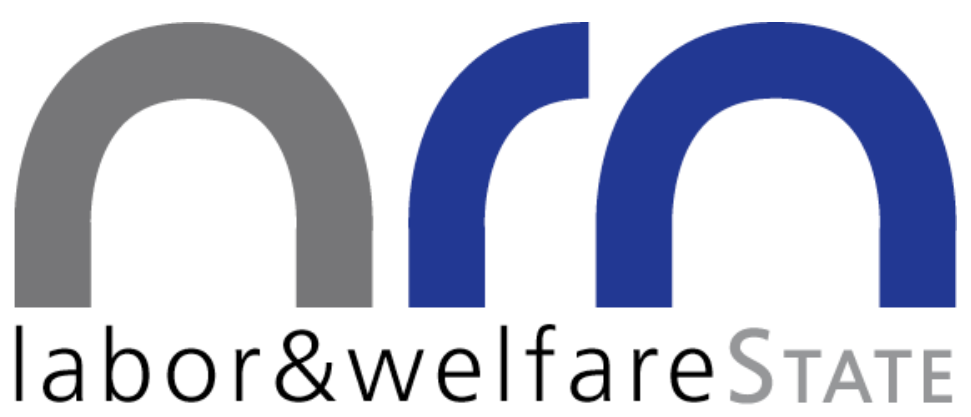

Tax Incentives and Family Labor Supply in Austria

by

Tibor HANAPPI

Sandra MÜLLBACHER

Working Paper No. 1212

November 2012

Supported by the

Austrian Science Funds

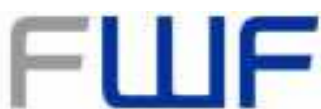

The Austrian Center for Labor Economics and the Analysis of the Welfare State

JKU Linz

Department of Economics

Altenberger Strasse 69

4040 Linz, Austria

www.labornrn.at 


\title{
Tax Incentives and Family Labor Supply in Austria
}

\author{
Tibor Hanappi*, University of Linz and IHS Vienna \\ Sandra Müllbacher, IHS Vienna
}

November 6, 2012

\begin{abstract}
This paper approaches the question whether and to what extent a policy shift from universal child transfers towards child tax deductibles is capable of activating (mostly female) unused labor market potential in Austria. We develop a discrete choice labor supply model based on the EU-SILC datasets 2004-2010 and present static uncompensated own and cross wage elasticities at the intensive and extensive margins. We find that the family policy reform 2009 had only small employment effects, most of them being generated through the introduction of a child care deductible. To illustrate the employment potential of a shift from transfers to tax deductibles we propose several simulations showing that such a policy shift would yield an increase in full time equivalents of approximately $1.3 \%$ overall, with females in couples increasing their labor supply by up to $3.9 \%$. Although the proposed policy shifts have highly regressive effects in terms of their impact on the distribution of disposable income, we show that phasing-out the tax deductible at higher income allows, in principle, for the compensation of lower-income households without jeopardizing positive employment effects.

Keywords: Labor Supply; Discrete Choice; Income Taxation; Family Policy
\end{abstract}

${ }^{*}$ Corresponding author: Tibor Hanappi, Institute for Advanced Studies, Stumpergasse 56, 1060 Vienna, Austria (hanappi@ihs.ac.at). For helpful discussion and comments we would like to thank Rudolf Winter-Ebmer and Helmut Hofer as well as the Austrian Central Bank for financial support by means of the Jubiläumsfonds (project 13358). 


\section{Introduction}

Individual labor supply elasticities are at the core of many highly policy relevant research questions. As such, they have been the subject of theoretical as well as empirical investigations for a long time. However, while assumptions regarding the relative magnitude of labor supply responses at different margins and for different subgroups are needed in order to derive specific policy recommendations in an optimal tax framework (Mankiw et al., 2009, Diamond and Saez, 2011), the empirical literature on labor supply elasticities reports only limited consensus (Blundell and MaCurdy, 1999). Due to the large variation in estimated elasticites across studies, however, a considerable amount of uncertainty remains with regard to policy analysis.

Manoli et al. (2011) discuss the consistency of empirical micro and macro elasticities, distinguishing between static steady-state elasticities (Hicks) and intertemporal subsitution elasticities (Frisch). Regarding the former, which are also the focus of this research, their meta-analysis (based on quasiexperimental estimates) suggests elasticities of .25 and .15 for the extensive and intensive margin, respectively 1 . In their recent survey Meghir and Phillips (2008) consider a wide range of studies based on different methodological approaches, datasets and time periods. While the large variation in estimated elasticities is generally confirmed, they propose the following general conclusions. First, hours of work are relatively inelastic for men and most responsive for married women and lone mothers. At the extensive margin, i.e. in terms of participation, women generally show the strongest response, while lower-educated are somewhat more responsive than higher-educated men.

While Bargain et al. (2011) argue that the majority of the variation in elasticities is driven by the choice of estimation method, they additionally mention the selection of relevant population groups and time periods as well as different types of data as potential sources. As a proposed remedy they estimate static labor supply elasticities for Europe and the US based on a common discrete choice framework. Their results show that cross-country differences in labor supply elasticities are in fact much more uniform once a common empirical strategy is applied. Static own-wage elasticities of total

\footnotetext{
${ }^{1}$ These are mean values over all studies in their analysis, however, the authors also present a larger estimate for the intensive margin elasticity which is derived through a different methodological approach. Since this approach accounts for optimization frictions they argue that the resulting elasticity corresponds better to the macro estimates.
} 
working hours are found to be in a range from .2 to .4 for married women in the majority of European countries (including Austria). While the US and some other European countries show slightly lower values, elasticities in southern European countries are higher and range between .4 and .6 for this population group. Elasticities for married men are compressed within the range from .05 to .15 , however, male and female singles have comparatively high hours elasticities ranging from 0 to .5 .

In this chapter we present new empirical evidence on labor supply in Austria based on a structural discrete choice model. This approach has initially been developed by Van Soest (1995) and Hoynes (1996). While the discretization of the individual decision problem implies a marginal loss of generality, it has strong advantages compared to continuous approaches (Creedy and Duncan, 2002). This mainly includes the facts that (i) it allows for highly non-convex budget sets which typically result from complex taxbenefit systems and that (ii) it is usually not necessary to exclude certain subgroups of the sample in order to identify effects. Additionally, increases in computational capacity enable more recent studies, such as ours, to expand the number of working hours categories such that a continuous representation of the decision problem can in fact be approximated. However, more recent research based on continuous models include Garcia and Suarez (2003) and Donni and Moreau (2007).

While discrete choice models often assume that unitary households decide jointly upon the spouses' labor supply, the collective approach developed by Chiappori (1992) overcomes this shortage through the introduction of a bargaining framework. In order to identify intra-household sharing rules in these types of models, however, studies typically have to restrict their sample e.g. to couples with full-time working males or without children (Donni, 2007; Chiappori and Donni, 2009). In general, the availability of consumption data facilitates identification, however, Bloemen (2010) recently proposed a discrete choice model with collective households based only on income and working hours data.

Although extensive quasi-experimental evidence on labor supply response has been collected with regard to tax-benefit reforms in the U.S. and the U.K. (Blundell et al., 1998; Meyer and Rosenbaum, 2001; Eissa and Hoynes, 2004), only few European studies use this approach. However, recent research has made some effort to validate structural discrete choice models through experimental evidence, as reported e.g. in Chemin and Wasmer (2011) or Hansen and Liu (2011). While these studies typically limit their samples 
to comparable subgroups, experimental results tend to affirm the structural estimates.

This chapter presents two main contributions. First, we develop a structural discrete choice model based on the tax-benefit microsimulation model ITABENA (Hofer et al., 2003; Dearing et al., 2007) and estimate labor supply elasticities at intensive and extensive margins for various household types and income quantiles in Austria. Second, we use the structural estimates to evaluate employment potential and redistributive effects of a shift from universal child transfers to child tax deductibles. As a starting point for the simulations, we first evaluate the family tax reform 2009 which initially introduced the child tax deductible (among other measures). In addition, we simulate counterfactual scenarios where the deductible is increased at the expense of universal child transfers. Although in other countries tax credits and deductibles are commonly used to improve work incentives for families (Hotz and Scholz, 2003; Brewer et al., 2006; Hotz et al., 2006), they have not yet been widely adopted in Austria. However, our simulations show that a revenue-neutral shift towards a child tax deductible that is phased-out with income yields considerable employment effects without necessarily making any household worse off in monetary terms.

The chapter is organized as follows. Section 2 discusses the data, while the econometric approach and the related results are presented in sections 3 and 4 respectively. Policy simulations are presented in section 5 and summarized in the conclusion 6 .

\section{Data}

Our analysis is based on the Austrian component of the European Statistics on Income and Living Conditions (EU-SILC). The data combines detailed information on income, household characteristics and labor supply, and has mainly been used for cross-sectional investigations. The present analysis, however, makes use of the longitudinal component by linking individuallevel data on a two-year basis so as to correct for a range of unintentional time-lags that arise out of the EU-SILC's survey design. Due to this correction the total amount of observations reduces to about $75 \%$ of the full sample. Additionally, we limit our analysis to those population groups that are considered flexible in terms of labor supply. We are thus excluding the following groups: Individuals with age below 15 or above statutory retirement 
age, self-employed, people in education, military/civilian service or receiving care-allowance, retirees and women right after childbirth. Since the longitudinal component of the Austrian EU-SILC becomes available with wave 2004, we are able to make use of six cross-sectional datasets enabling us to construct a pooled dataset containing information from five consecutive years. After these corrections we are able to draw on a total of 14288 observations, consisting of 3219 female and 2915 male individuals without or with inflexible partner and 4077 households with two flexible adults each.

\section{Model Specification}

We estimate labor supply elasticities on the basis of a static discrete choice model. In fact, to account for different household contexts we define and estimate three seperate models, one for female and male individuals, respectively, and a unitary household model which views spouses as joint decision makers. In the former, decision makers are either singles or have partners with inflexible labor supply. In unitary households the labor supplies of both spouses are allowed to vary, however, preferences are represented by a single household utility function.

Following Van Soest (1995) we interpret labor supply as a choice that households $n=1, \ldots, N$ take from a discrete set of alternatives $j=1, \ldots, J$. Each alternative consists of a combination $\left(y_{n j}, m_{n j}, f_{n j}\right)$, where $y_{n j}$ represents household disposable income, and $m_{n j}$ and $f_{n j}$ represent male and female leisure time respectively $\left.\right|^{2}$. Hours worked, $h_{n j}^{m}$ and $h_{n j}^{f}$, are defined by the total time endowment per week (168 hours) minus corresponding leisure time, so that disposable income of household $n$ in alternative $j$ is defined by:

$$
y_{n j}=w_{n}^{m} h_{n j}^{m}+w_{n}^{f} h_{n j}^{f}-\tau\left(w_{n}^{m} h_{n j}^{m}, w_{n}^{f} h_{n j}^{f} ; Z_{n}\right)
$$

Disposable income is thus a function of female and male working hours times their respective gross hourly wage rates, $w_{n}^{m}$ and $w_{n}^{f}$, minus net taxes. The tax-benefit function $\tau$ depends on gross wage income and household characteristics $Z_{n}$. In order to calculate net taxes and thus also disposable income at different hours points we employ the tax-benefit microsimulation model

\footnotetext{
${ }^{2}$ In households with only one decision maker the choice problem has a reduced form depending on only two alternative-specific variables.
} 
ITABENA, which covers all major position ${ }^{3}$ within the Austrian tax-benefit system and has been documented in detail by Hofer et al. (2003). The discrete approach has the advantage that it combines tractability with a detailed representation of the household budget set including any non-convexities that arise due to the complexity of the Austrian tax-benefit system (Creedy and Duncan, 2002).

Table 1: Observed hours levels in households with one flexible adult (\%)

\begin{tabular}{llllllll}
\hline \hline & $\mathbf{0}$ & $\mathbf{1 - 1 0}$ & $\mathbf{1 1 - 2 0}$ & $\mathbf{2 1 - 3 0}$ & $\mathbf{3 1 - 4 0}$ & $\mathbf{4 0 +}$ & Total \\
\hline Men & $179(6)$ & $7(0)$ & $44(2)$ & $68(2)$ & $1795(62)$ & $822(28)$ & $\mathbf{2 9 1 5}$ \\
\hline Women & $626(19)$ & $77(2)$ & $337(10)$ & $453(14)$ & $1406(44)$ & $320(10)$ & $\mathbf{3 2 1 9}$ \\
\hline \hline
\end{tabular}

Table 2: Observed hours levels in households with two flexible adults (\%)

\begin{tabular}{llllllll}
\hline \hline $\mathbf{m} \backslash \mathbf{w}$ & $\mathbf{0}$ & $\mathbf{1 - 1 0}$ & $\mathbf{1 1 - 2 0}$ & $\mathbf{2 1 - 3 0}$ & $\mathbf{3 1 - 4 0}$ & $\mathbf{4 0}+$ & Total \\
\hline $\mathbf{0}$ & 75 & 4 & 13 & 18 & 47 & 12 & $169(4)$ \\
$\mathbf{1 - 1 0}$ & 0 & 0 & 0 & 0 & 1 & 1 & $2(0)$ \\
$\mathbf{1 1 - 2 0}$ & 5 & 2 & 8 & 7 & 7 & 0 & $29(1)$ \\
$\mathbf{2 1 - 3 0}$ & 22 & 2 & 11 & 19 & 13 & 0 & $67(2)$ \\
$\mathbf{3 1 - 4 0}$ & 755 & 104 & 484 & 440 & 707 & 83 & $2573(3)$ \\
$\mathbf{4 0}+$ & 390 & 47 & 218 & 192 & 274 & 116 & $1237(30)$ \\
\hline Total (\%) & $1247(31)$ & $159(4)$ & $734(18)$ & $676(17)$ & $1049(26)$ & $212(5)$ & $\mathbf{4 0 7 7}$ \\
\hline \hline
\end{tabular}

In order to discretize the choice set we divide the continuum of possible working hours into six categories and define the hours level as the median in the respective category. We thus have slightly different hours points for males, $h^{m} \in\{0,8,20,29,40,44\}$, and females, $h^{f} \in\{0,8,20,27,40,43\}$, and a total of 36 possible choice alternatives for households with two flexible adults (cf. tables 1 and 22). The gross hourly wage rates, $w_{n}^{m}$ and $w_{n}^{f}$, are either calculated arithmetically from observed working hours (including overtime), months of employment and gross yearly income or estimated using a Heckman model to correct for sample selection 4 . The distribution of gross

\footnotetext{
${ }^{3}$ Specifically, it incorporates income taxation, employee's contributions to social insurance, welfare benefits as well as family tax credits and transfers.

${ }^{4}$ The wage regressions are estimated seperately for males and females in each crosssection. We use number of children, health status and previous labor market states as exclusion restrictions and adjust the variance of the wage distribution of the non-employed
} 
hourly wage rates shows comparable levels for non-employed males and females, while employed men have significantly higher wage rates than their female counterparts (see table 3). In order to derive disposable incomes at different hours points on the basis of equation (1) we additionally assume that wage rates are independent of working hours.

Table 3: Gross hourly wage rates including overtime

\begin{tabular}{rclllllll}
\hline \hline Women & mean (sd) & $\mathrm{p} 5$ & $\mathrm{p} 10$ & $\mathrm{p} 25$ & $\mathrm{p} 50$ & $\mathrm{p} 75$ & $\mathrm{p} 90$ & $\mathrm{~N}$ \\
\hline Non-Employed & $7.87(3.23)$ & 4.27 & 4.73 & 5.73 & 7.09 & 9.13 & 11.76 & 2295 \\
Employed & $14.16(6.30)$ & 6.56 & 7.64 & 9.67 & 12.64 & 17.30 & 23.03 & 5453 \\
& & & & & & & & \\
Men & mean (sd) & $\mathrm{p} 5$ & $\mathrm{p} 10$ & $\mathrm{p} 25$ & $\mathrm{p} 50$ & $\mathrm{p} 75$ & $\mathrm{p} 90$ & $\mathrm{~N}$ \\
\hline Non-Employed & $12.25(6.87)$ & 4.33 & 5.10 & 6.73 & 10.45 & 16.18 & 22.89 & 662 \\
Employed & $17.37(7.06)$ & 8.94 & 10.00 & 12.33 & 15.75 & 20.85 & 27.70 & 6528 \\
\hline \hline
\end{tabular}

Utility is defined by a systematic part $V_{n j}=V\left(y_{n j}, m_{n j}, f_{n j} ; Z_{n}\right)$ which subsumes observed information on choice alternatives and household characteristics, and an unobserved part which is described by a random term $\epsilon_{n j}$ following a type I extreme value distribution: $U_{n j}=V_{n j}+\epsilon_{n j}, \forall n, j$. Under the assumption that observed (male and female) working hours represent utility maximizing choices conditional on the household budget set, this specification is equivalent to a conditional logit model as described e.g. in Train (2009). Our analysis further assumes that the systematic part $V_{n j}$ is a quadratic function of the alternative-specific variables $\left(y_{n j}, m_{n j}, f_{n j}\right)$ and (potentially) includes interaction terms.

$$
\begin{aligned}
V_{n j}=\bar{\alpha}_{y} y_{n j} & +\bar{\alpha}_{m} m_{n j}+\bar{\alpha}_{f} f_{n j}+\beta_{y 2} y_{n j}^{2}+\beta_{m 2} m_{n j}^{2}+\beta_{f 2} f_{n j}^{2} \\
& +\beta_{y m} y_{n j} m_{n j}+\beta_{y f} y_{n j} f_{n j}+\beta_{m f} m_{n j} f_{n j}+\bar{\delta} D_{n j}
\end{aligned}
$$

Observed heterogeneity among households enters the specification through the vectors $\bar{\alpha}_{y}, \bar{\alpha}_{m}$ and $\bar{\alpha}_{f}$. Each vector contains a parameter measuring the direct preference for income, male or female leisure and an additional vector of parameters, $\bar{\gamma}_{y}, \bar{\gamma}_{m}$ or $\bar{\gamma}_{f}$, measuring the effect of each of the household

by adding randomly drawn wage residuals. Estimation tables and related results are available from the authors on request. 
characteristics $Z_{n}$ on the preference for the corresponding variable.

$$
\begin{array}{r}
\bar{\alpha}_{y}=\beta_{y}+Z_{n}^{\prime} \bar{\gamma}_{y} \\
\bar{\alpha}_{m}=\beta_{m}+Z_{n}^{\prime} \bar{\gamma}_{m} \\
\bar{\alpha}_{f}=\beta_{f}+Z_{n}^{\prime} \bar{\gamma}_{f}
\end{array}
$$

The total set of estimated parameters thus consists of direct preference parameters $\beta_{y}, \beta_{m}, \beta_{f}, \beta_{y 2}, \beta_{m 2}, \beta_{f 2}, \beta_{y m}, \beta_{y f}$ and $\beta_{m f}$ as well as an additional set of taste-shifting parameters captured by $\bar{\gamma}_{y}, \bar{\gamma}_{m}$ and $\bar{\gamma}_{f}$. Fixed costs of work are introduced through a set of male and female indicators for full and part-time alternatives, $D_{n j}$, thus further increasing the flexibility of the functional form. The exact specification of interaction terms and taste-shifting parameters varies across household and individual models (cf. tables 4,5 and 6) and will be discussed in the next section.

\section{Estimation Results}

Based on the specifications discussed in the previous section we derive the log-likelihood function for each of the three separate models and estimate parameters through maximum likelihood (cf. tables 4,5 and 6). The estimates are hard to interpret directly, due to the fact that preferences depend not only on a direct effect $\left(\beta_{y}, \beta_{m}, \beta_{f}\right)$ but also on quadratic and interaction terms $\left(\beta_{y 2}, \beta_{m 2}, \beta_{f 2}, \beta_{y m}, \beta_{y f}\right.$, and $\left.\beta_{m f}\right)$ as well as on the combined effect of all relevant taste-shifting parameters $\left(\bar{\gamma}_{y}, \bar{\gamma}_{m}\right.$ and $\left.\bar{\gamma}_{f}\right)$.

All estimated parameters for the main explanatory variables have the expected signs and high levels of significance. Direct preferences for income are all positive and highly significant, preferences for leisure are also positive throughout all three models, although the significance level in the male model is somewhat lower. Negative parameter estimates for the quadratic income terms allow for decreasing marginal utilities of individuals and households, however, quadratic leisure terms are only included in the individual models. Interaction terms between income and (male or female) leisure are negative and significant throughout all models, thus pointing to a certain substitutability between the two. For unitary households the interaction between male and female leisure is negative and highly significant, indicating that the two 'types' of leisure can be subsituted on the household level. Taste-shifting parameters are depicted in tables 4 , 5 and 6, where we include 
Table 5: Individual model estimates: men without or with inflexible partner

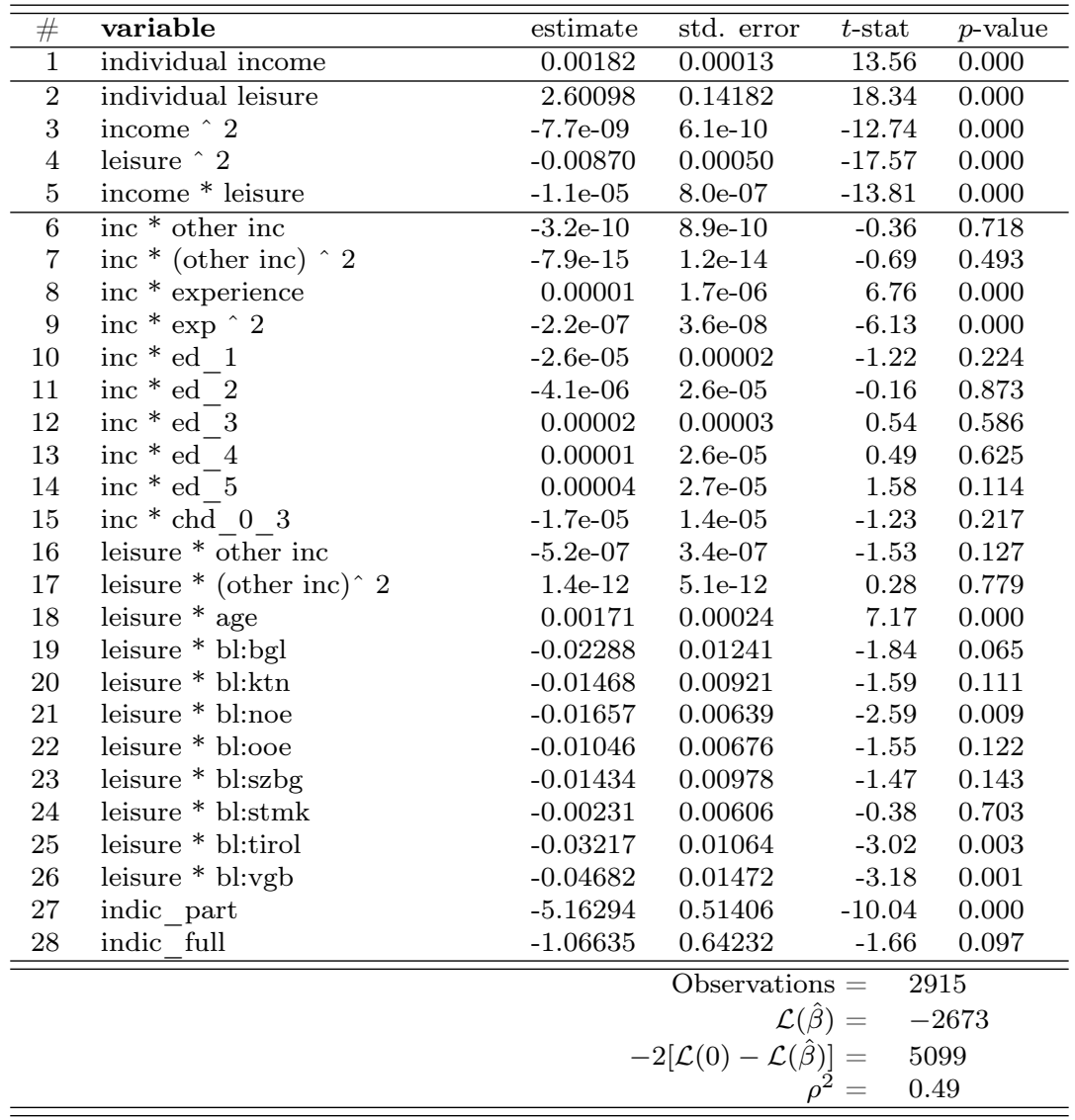

household level transfers plus rents and income from capital ownership.

To allow for a more comprehensive interpretation we derive first and second derivatives with respect to income and leisure based on the full set of estimated parameters. Since the quadratic specification of utility does not entail any a priori assumption on the signs of the derivatives (Creedy and Duncan, 2002), we check whether the estimated parameter values result in a function that satisfies the following conditions for quasiconcavity at the observed labor supply points: (1) $\partial U / \partial y>0, \partial U / \partial y 2<0$ and (2) $\partial U / \partial l>$ $0, \partial U / \partial l 2<0$. While increasing monotonicity in income is satisfied for close to $100 \%$ of the sample 5 , condition (2) is true for about $80 \%$. Although this

\footnotetext{
${ }^{5}$ Note that for the policy simulations we exclude indviduals who do not satisfy this condition.
} 
Table 6: Individual model estimates: women without or with inflexible partner

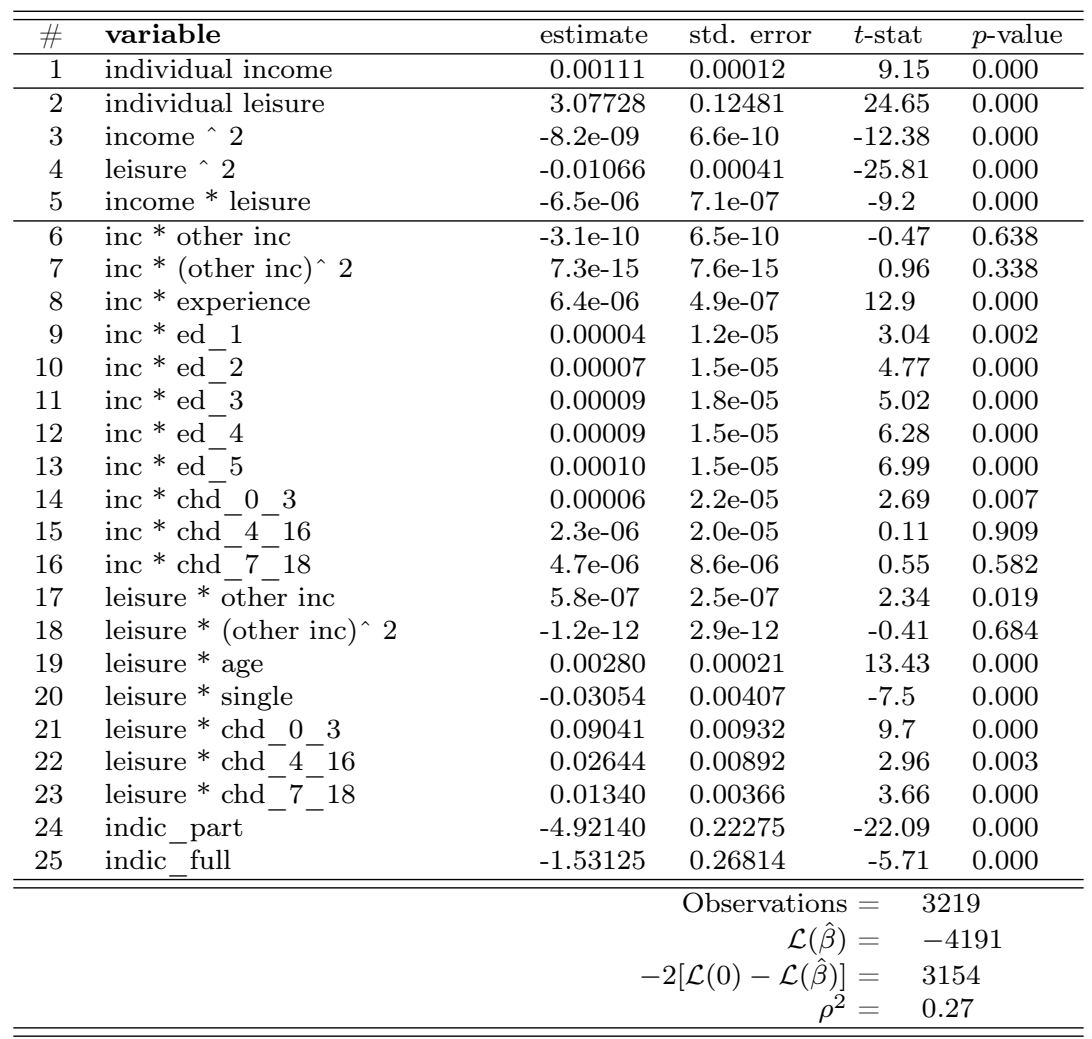

result implies that for some individuals utility is not monotonically increasing in leisure, we do not impose any restrictions with regard to this condition.

Based on our estimates we first calculate choice probabilities for each individual and each hours category in the base scenario. Expected working hours are then derived by multiplying the probabilities with the median working hours of the respective category and summing up. Our model thus predicts average working times of 38.67 and 22.88 hours per week for males and females respectively, which comes very close to the average values in the sample, 38.84 and 22.47 .

To derive labor supply elasticities we increase gross wage income by $1 \%$ and calculate expected working hours under the reform scenario. The hours elasticity is computed as the relative difference in expected working hours between base and reform scenario (intensive margin), while the participation 
elasticity is given by the absolute difference in participation probabilities (extensive margin). These results thus represent static uncompensated unconditional own and cross wage elasticities, as depicted in tables 7 and 8 .

Table 7: Increase in male gross wage: $1 \%$

\begin{tabular}{|c|c|c|c|c|c|c|c|}
\hline \multicolumn{8}{|c|}{ Individual men: own wage elastici } \\
\hline & mean & p10 & p25 & $\mathrm{p} 50$ & p75 & p90 & $\mathrm{N}$ \\
\hline hou & 0.226 & 0.021 & 0.049 & 0.111 & 0.238 & 0.538 & 2548 \\
\hline part. & 0.133 & 0.007 & 0.022 & 0.064 & 0.166 & 0.367 & 2548 \\
\hline
\end{tabular}

Men in couples: own wage elasticity

\begin{tabular}{rrrrrrrr}
\hline & mean & $\mathrm{p} 10$ & $\mathrm{p} 25$ & $\mathrm{p} 50$ & $\mathrm{p} 75$ & $\mathrm{p} 90$ & $\mathrm{~N}$ \\
\hline hours & 0.0997 & 0.016 & 0.034 & 0.070 & 0.130 & 0.223 & 3702 \\
part. & 0.072 & 0.007 & 0.019 & 0.047 & 0.094 & 0.170 & 3702
\end{tabular}

Women in couples: cross wage elasticity

\begin{tabular}{rrrrrrrr}
\hline & mean & $\mathrm{p} 10$ & $\mathrm{p} 25$ & $\mathrm{p} 50$ & $\mathrm{p} 75$ & $\mathrm{p} 90$ & $\mathrm{~N}$ \\
\hline hours & -0.222 & -0.576 & -0.348 & -0.200 & -0.105 & -0.025 & 4077 \\
part. & -0.080 & -0.235 & -0.140 & -0.076 & -0.035 & 0.001 & 4077 \\
\hline \hline
\end{tabular}

Our results correspond well to the empirical consensus discussed in the introductory section 1. Own-wage elasticites are positive throughout all household types, with females in couples being the most responsive subgroup in terms of hours and participation elasticities. This group has an average hours elasticity of .35 with individual values ranging from .18 at the first to .51 at the third quartile. While single females ${ }^{6}$ show almost the same responsiveness on average, variability is somewhat higher with half of this group's hours elasticities being between .08 and .62. Single men show an average hours elasticity of .22, however, an interquartile range from .05 to .24 implies that some of these males have comparatively high elasticites. Males in couples, on the other hand, are the least responsive subgroup, with hours elasticities varying between .03 and .13 over the interquartile range. An average cross-wage elasticity of -.22 shows that females respond to male wage increases by reducing their labor supply significantly. Male responses to female wage increases, however, tend to be minimal.

The presented elasticities for men and women in couples are almost identical to the results for Austria reported in Bargain et al. (2011). While the hours elasticity for single men is in a comparable range, our estimates for

\footnotetext{
${ }^{6}$ Note that we include individuals with inflexible partners when we speak of singles.
} 
Table 8: Increase in female gross wage: $1 \%$

\begin{tabular}{|c|c|c|c|c|c|c|c|}
\hline \multicolumn{8}{|c|}{ Individual women: own wage elasticity } \\
\hline & mean & p10 & $\mathrm{p} 25$ & $\mathrm{p} 50$ & p75 & p90 & $\mathrm{N}$ \\
\hline hours & 0.363 & 0.003 & 0.079 & 0.260 & 0.620 & 0.926 & 2953 \\
\hline part. & 0.156 & 0.012 & 0.039 & 0.117 & 0.249 & 0.379 & 2953 \\
\hline \multicolumn{8}{|c|}{ Women in couples: own wage elasticity } \\
\hline & mean & $\mathrm{p} 10$ & p25 & p50 & p75 & p90 & $\mathrm{N}$ \\
\hline hours & 0.347 & 0.058 & 0.181 & 0.340 & 0.511 & 0.713 & 4077 \\
\hline part. & 0.161 & 0.024 & 0.074 & 0.163 & 0.249 & 0.320 & 4077 \\
\hline \multicolumn{8}{|c|}{ Men in couples: cross wage elasticity } \\
\hline & mean & $\mathrm{p} 10$ & $\mathrm{p} 25$ & $\mathrm{p} 50$ & $\mathrm{p} 75$ & p90 & $\mathrm{N}$ \\
\hline hours & 0.019 & -0.006 & -0.002 & 0.005 & 0.021 & 0.054 & 3702 \\
\hline part. & 0.018 & -0.002 & 0.000 & 0.006 & 0.021 & 0.049 & 3702 \\
\hline
\end{tabular}

single females appear to be considerably higher. Although model specifications are not completely alike, a large part of this difference might as well be explained by the fact that our analysis uses a pool of much more recent cross-sections (i.e. 2004 to 2009). However, Steiner and Wakolbinger (2009) present labor supply elasticities for Austria based on a discrete choice model estimated on cross-sectional data from 2006. While their presented estimates have comparable magnitudes for most subgroups, they find somewhat lower hours elasticities for single males and females in couples. Recent studies from other countries, such as e.g. Germany (Steiner and Wrohlich, 2004, Peichl et al., 2010) or Belgium (Orsini, 2006), are in similar ranges.

For further interpretation of these elasticities we present two additional sets of results. First, figure 1 shows box plots for own-wage hours elasticities by household types and income quintiles (based on individual disposable income in the respective subgroup). Irrespective of the income quintile elasticities for males in couples are low and compressed within a range similar to that of the overall average. However, while individual males in higher quintiles have about the same elasticities as males in couples, labor supply responses of males in the first quintile are more dispersed and generally higher than in other quintiles. Female results confirm this pattern, as females in couples have similar elasticities independent of their income quintile while single females in the first quintile show comparatively strong responses 7 .

\footnotetext{
[Wernhart and Winter-Ebmer (2012) recently used a three-stage procedure to estimate
} 
Figure 1: Own-Wage Hours Elasticities by Income Quintile
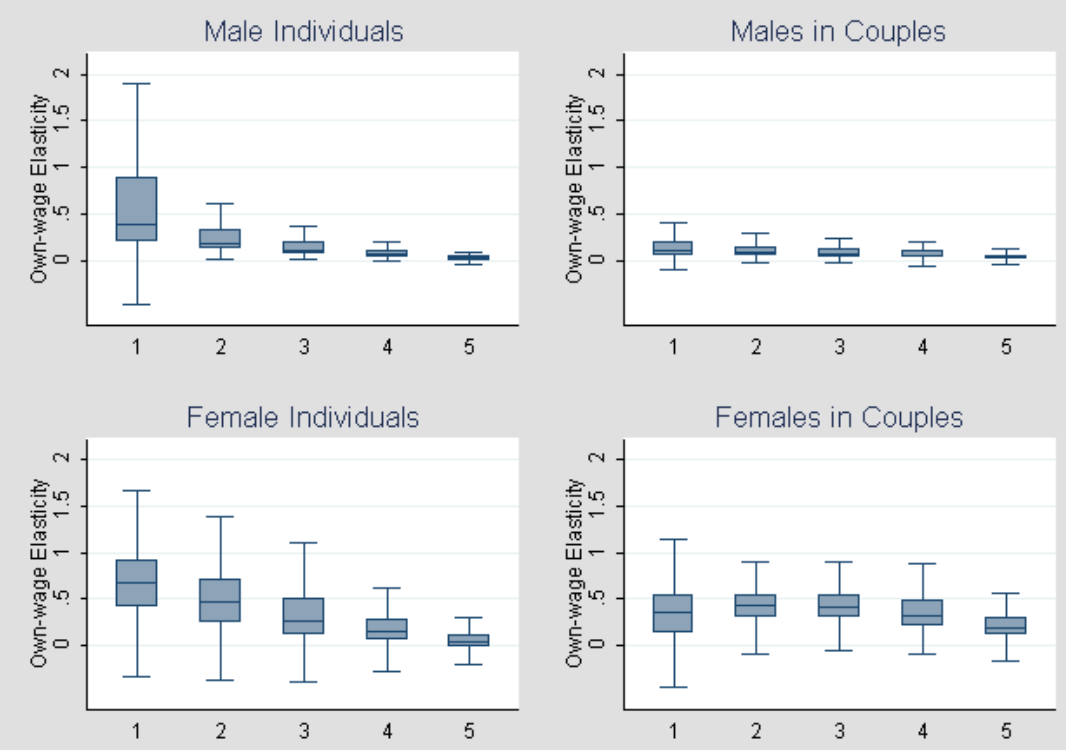

Note that income quintiles are computed on the basis of individual disposable income in each subgroup.

Table 9: Decomposition: Extensive and Intensive Margins

\begin{tabular}{rrrr}
\hline \hline & intensive & extensive & total elasticity \\
\hline male individuals & 0.058 & 0.169 & 0.227 \\
males in couples & 0.021 & 0.079 & 0.099 \\
\hline female individuals & 0.098 & 0.248 & 0.347 \\
females in couples & 0.088 & 0.254 & 0.343 \\
\hline \hline
\end{tabular}

Second, we take a closer look at labor supply responses at intensive and extensive margins through a decomposition of the total response in working hours induced by a $1 \%$ increase in wages. Therefore, we decompose labor supply responses at the individual level into changes in working hours due to

labor supply elasticites in Austria based on repeated cross-sections from 1981-1999. Although their preferred estimates are lower than ours (possibly due to different empirical strategies), they confirm our results with regard to the similarity of male and female labor supply patterns. 
increases in participation probabilities and changes in working hours due to increases in expected working hours conditional on participation. As table 9 depicts for each subgroup, the increase in total working hours is clearly driven by the extensive margin, thus confirming recent results in Bargain et al. (2011).

This set of results is relevant for the design of reform policies discussed in the next section. While tax incentives for working individuals have the desirable property to encourage labor market participation, these measures become very costly in case they are not phased out at higher incomes. The phase-out, on the other hand, is associated with adverse labor supply effects since individuals have an incentive to reduce working hours so as to be still eligible for the relevant tax credits or deductibles (Diamond and Saez, 2011). However, our empirical results show that labor supply responses at the intensive margin are small compared to the effect of labor market participation. Since there will be more non-participating individuals at the lower end of the income distribution, this result thus corresponds to the fact that overall hours elasticities are higher in lower income quintiles. As discussed in the next section, these results suggest that tax incentives which are phased out at higher incomes have the potential to increase employment without incurring strong negative behavioural reactions.

\section{Policy Simulations}

In Austria total expenditures on family policy make up around $2.9 \%$ of GDP, where direct monetary transfers are clearly favored over in-kind transfers, tax credits and deductibles. While Austria thus ranks in the upper third of OECD countries with regard to expenditures, it lags behind with regard to some family policy objectives (OECD, 2011). Although outcomes are satisfactory with respect to child poverty and early age development, fertility is decreasing while the gap between male and female employment rates remains higher than in comparable OECD countries. In addition, part-time employment is very common among women and the share of mothers in paid work is only around the OECD average (Lutz and Schratzenstaller, 2010).

This section thus explores employment and redistributive effects of several counterfactual policy simulations on the basis of the labor supply estimates just discussed. As noted above, family policy in Austria relies heavily on monetary transfers consisting of two main components: the universal child 
transfer and a child tax credit which is fully reimbursed as a negative tax (thus making it a pure transfer). However, a recent reform, taking effect in 2009, introduced tax deductibles as new policy instruments. Apart from modest increases in monetary transfers two distinct tax deductibles were introduced: First, a general tax deductible for each child and, second, a tax deductible for child care expenditures.

The child tax deductible is 220 euro per year in case only one parent claims it, and 132 euro per year and person in case both do. Therefore, in its present form, the deductible (i) amounts to only very small magnitudes and (ii) does not explicitly encourage the equal division of paid work among parents. The child care deductible, on the other hand, allows for reductions in taxable income of up to 2300 euro per year and child, depending on the actual amount of child care expenditures in the household. Both of these new components represent tax deductibles in the sense that they are subtracted from taxable income before the corresponding tax rate is applied, thus giving rise to different amounts of tax savings depending on individual marginal tax rates.

Table 10: Family Policy Reform 2009 (million euro / fulltime equivalents (FTE))

\begin{tabular}{rrrrr}
\hline \hline government revenue & overall & transfer & deductible & child care \\
\hline $1^{\text {st }}$ round & -391 & -152 & -132 & -108 \\
$2^{\text {nd }}$ round & 38 & -0.5 & 6 & 38 \\
total & -351 & -152 & -126 & -70 \\
\hline employment & & & & \\
\hline fulltime equivalents & 6,056 & 32 & 891 & 5,291 \\
percent of total FTE & 0.3 & 0.0 & 0.0 & 0.3 \\
\hline \hline
\end{tabular}

Simulation results for the complete reform package 2009 are shown in table 10. The immediate budgetary effects make up around 391 million euro in total, where the increase in transfers and the child tax deductible have approximately equal proportions and the child care deductible accounts for somewhat less. In terms of labor supply effects, however, the tax deductibles have positive effects while the child transfer shows basically no impact. By far the largest effect is due to the child care tax deductible, as subsidization of child care directly reduces the cost of an additional hour of work (as e.g. in Wrohlich (2006)). Accounting for labor supply responses the overall cost of the reform bundle thus reduces considerably, i.e. to around 351 million 
euro.

To further illustrate potential employment effects of the newly introduced child tax deductible we simulate several reform scenarios and combine them into revenue neutral policy shifts. Therefore we first simulate two scenarios with reduced child transfers and four scenarios with increased child tax deductibles including differential treatment of first and second earners 8 . Ensuring revenue neutrality these simulations are then combined to four policy shifts denoted as $\phi_{s e}, \phi_{s d}, \phi_{l e}$ and $\phi_{l d}$ in table 11. While these shifts are either small (subscript $s$ ) or large (subscript $l$ ) in terms of overall volume, they also differ with regard to the treatment of second earners: simulations $\phi_{s e}$ and $\phi_{l e}$ imply equal deductions for first and second earners, $\phi_{s d}$ and $\phi_{l d}$ imply differential treatment in the sense that second earners have access to higher deductions.

Table 11: Policy Shifts: Simulated Transfers and Deductibles

\begin{tabular}{rrrrr}
\hline \hline & transfer & \multicolumn{3}{c}{ deductibles } \\
\cline { 3 - 5 } & & first earner & second earner & single earner \\
\hline$\phi_{s e}$ & 100 & 3,092 & 3,092 & 6,184 \\
$\phi_{s d}$ & 100 & 2,712 & 5,424 & 8,136 \\
$\phi_{l e}$ & 0 & 7,843 & 7,843 & 15,686 \\
$\phi_{l d}$ & 0 & 7,286 & 14,572 & 21,858 \\
\hline \hline
\end{tabular}

Note: (a) in the base scenarios universal child transfers amount to $160-260$ euro per child and month until the maximum age of 24 .

(b) Transfers are given in euro per child and month, deductibles refer to yearly euros per child; (c) single earners always get the sum of first and second earners.

All of the scenarios are evaluated against the status-quo before the family policy reform 2009. The large policy shifts represent a complete cut back of the universal child transfer which amounts to about 160-260 euro per child and month until the maximum age of $24^{9}$. Simulations $\phi_{l e}$ and $\phi_{l d}$ thus correspond to a shift in government expenditures by a magnitude of approximately 3.8 billion euro. The two smaller policy shifts, on the other hand, represent a less severe cut back, since a universal child transfer of 100 euro per child and year is still granted. Simulations $\phi_{s e}$ and $\phi_{s d}$ are thus associated with a volume of about 1.8 billion euro. However, all four policy shifts are revenue neutral in the sense that, after accounting for first and second round effects, they do not alter government expenditures.

In terms of overall employment effects smaller volume policy shifts yield

\footnotetext{
${ }^{8}$ Results from the first six reform scenarios are not reported here since they are only
} 
Table 12: Policy Shifts: Employment Effects

\begin{tabular}{rrrrrrrrr}
\hline \hline & \multicolumn{2}{c}{$\phi_{\text {se }}$} & \multicolumn{2}{c}{$\phi_{\text {sd }}$} & \multicolumn{2}{c}{$\phi_{l e}$} & \multicolumn{2}{c}{$\phi_{l d}$} \\
\cline { 2 - 9 } & $\mathrm{FTE}$ & $\%$ & $\mathrm{FTE}$ & $\%$ & $\mathrm{FTE}$ & $\%$ & $\mathrm{FTE}$ & $\%$ \\
\hline female individuals & 4,409 & 1.0 & 5,076 & 1.1 & 6,038 & 1.3 & 6,221 & 1.4 \\
females in couples & 7,501 & 2.0 & 10,781 & 2.9 & 11,969 & 3.3 & 14,353 & 3.9 \\
male individuals & 1,334 & 0.2 & 1,262 & 0.2 & 2,180 & 0.3 & 2,135 & 0.3 \\
males in couples & 3,912 & 0.6 & 3,807 & 0.5 & 6,530 & 0.9 & 6,303 & 0.9 \\
\hline total & 17,156 & - & 20,927 & - & 26,718 & - & 29,012 & - \\
\hline \hline
\end{tabular}

Note: Percentage values in each line refer to aggregate fulltime equivalents in the respective group.

increases of up to $0.94 \%$ of total aggregated FTE on the supply side of the labor market (20,927 FTE), while the two larger volume shifts reach up to $1.31 \%$ (or 29,012 FTE). Employment effects by household type are summarized in table 12. Male individuals show the lowest response throughout all simulations, ranging up to only .3\% of their total FTE. While males in couples react somewhat stronger, the associated relative increase in FTE remains low in this subgroup. For female individuals absolute FTE increases have about the same magnitude, however, they make up a much larger proportion, i.e. between 1 and 1.4\%, of total FTE in this subgroup. By far the largest proportion of the total labor supply response is driven by females in couples who are shown to increase FTE by 2 to $3.9 \%$ of their total depending on the scenario.

Regarding differential treatment of second earners, our simulations show that such a policy design has the potential to yield significant increases in female labor supply. Without increasing the overall volume of the policy shift advantageous treatment of second earners increases overall labor supply by about 3,000 FTE, thus corresponding to an increase of up to .9 percentage points in this group. While the effectiveness of such policies will be further increased through investments in child care institutions, our results show that they present an effective way to strengthen the link between working hours of second earners and disposable household income (thus creating positive jointness between spousal earnings' as defined in Immervoll et al. (2009)).

Although the proposed policy shifts imply strong responses in labor supply, decomposing the results by income deciles shows that they also have a large impact on the distribution of disposable incomes. Table 5 summa-

used to ensure revenue neutrality.

${ }^{9}$ Transfers can only be received until age 24 if the child is still in education. 
Table 13: Policy Shifts: Labor Supply and Distributive Effects by Income Deciles

\begin{tabular}{rrrrrrrrr}
\hline \hline & \multicolumn{2}{c}{$\phi_{s e}$} & \multicolumn{2}{c}{$\phi_{s d}$} & \multicolumn{2}{c}{$\phi_{l e}$} & \multicolumn{2}{c}{$\phi_{l d}$} \\
\cline { 2 - 9 } decile & $\Delta \mathrm{FTE}$ & $\Delta \mathrm{Y}$ & $\Delta \mathrm{FTE}$ & $\Delta \mathrm{Y}$ & $\Delta \mathrm{FTE}$ & $\Delta \mathrm{Y}$ & $\Delta \mathrm{FTE}$ & $\Delta \mathrm{Y}$ \\
\hline 1 & 0.06 & -161 & 0.06 & -162 & 0.07 & -494 & 0.07 & -496 \\
2 & 0.08 & -84 & 0.08 & -87 & 0.11 & -224 & 0.11 & -226 \\
3 & 0.12 & 16 & 0.13 & -1 & 0.17 & -46 & 0.17 & -53 \\
4 & 0.12 & 57 & 0.14 & 45 & 0.19 & 63 & 0.19 & 55 \\
5 & 0.13 & 74 & 0.16 & 81 & 0.23 & 99 & 0.23 & 89 \\
6 & 0.13 & 77 & 0.17 & 79 & 0.22 & 177 & 0.25 & 166 \\
7 & 0.05 & 66 & 0.07 & 77 & 0.09 & 147 & 0.10 & 143 \\
8 & 0.03 & 113 & 0.05 & 139 & 0.05 & 255 & 0.06 & 255 \\
9 & 0.03 & 129 & 0.05 & 159 & 0.05 & 312 & 0.08 & 346 \\
10 & 0.02 & 90 & 0.03 & 134 & 0.02 & 314 & 0.04 & 389 \\
\hline total & $\mathbf{0 . 7 7}$ & - & $\mathbf{0 . 9 4}$ & - & $\mathbf{1 . 2 0}$ & - & $\mathbf{1 . 3 1}$ & - \\
\hline \hline
\end{tabular}

Note: (a) $\triangle$ FTE stands for changes in FTE relative to overall aggregates; (b) $\Delta \mathrm{Y}$ stands for changes in individual disposable incomes (in million euro) accounting for first and second round effects.

rizes employment and distributional effects per decile for each policy shift. Since there are more children in lower deciles, cut backs in universal transfers have a stronger impact on households in these deciles. Additionally, the child deductible reinforces this distributional effect due to the fact that it reduces over-proportionally the tax liabilities of high-income households and individuals. Corresponding to these distributional effects the majority of the increase in FTE is realized by workers in deciles 2-6, thus implying that behavioural responses markedly counteract adverse distributional effects in this region of the income distribution. In fact, once labor supply reactions are taken into account first round losses in disposable income are offset by second round increases for deciles 4 and 510 . While the third decile still has to accomodate small overall decreaes in disposable income (in $\phi_{s d}, \phi_{l e}$ and $\left.\phi_{l e}\right)$, overall losses remain substantial in deciles 1 and 2 .

In total, lower deciles lose approximately 250 and 770 million euro due to small and large policy shifts respectively. While, in absence of a social welfare function, we are unable to comment on the desirability of redistributive measures, these numbers represent quite large volumes and we thus present some further evidence showing that lower-income individuals can in fact be compensated without jeopardizing postive employment effects. Therefore we present additional simulations, $\bar{\phi}_{s e}, \bar{\phi}_{s d}, \bar{\phi}_{l e}$ and $\bar{\phi}_{l d}$, which are exactly the

\footnotetext{
${ }^{10}$ First round distributional effects are not reported here.
} 
same as before except for the fact that child tax deductibles are now phasedout for higher incomes. Although such phase-outs are a common feature of tax-benefit systems in other countries (cf. Blundell et al. (2000); Hotz and Scholz (2003)), they are only rarely applied in the context of Austrian family policy ${ }^{11}$.

In order to show that it is, in principle, possible to achieve these policy shifts without making any individual worse off in monetary terms, we propose a set of phasing-out thresholds and rates such that the overall increase in government revenues exactly matches absolute losses in disposable incomes in the lower deciles ${ }^{12}$. For small scale policy shifts, $\bar{\phi}_{s e}, \bar{\phi}_{s d}$, phase-out begins at a rate of .3 as soon as a yearly gross income of 45,000 euro is reached. Due to higher overall volumes, large scale policy shifts, $\bar{\phi}_{l e}$ and $\bar{\phi}_{l d}$, require a threshold of 35,000 in yearly gross income combined with a phase-out rate of .4 in order to break even. Results are depicted in table 5.

Table 14: Policy Shifts with Phase-Out: Labor Supply and Distributive Effects

\begin{tabular}{rrrrrrrrr}
\hline \hline & \multicolumn{2}{c}{$\phi_{s e}$} & \multicolumn{2}{c}{$\phi_{s d}$} & \multicolumn{2}{c}{$\phi_{l e}$} & \multicolumn{2}{c}{$\phi_{l d}$} \\
\cline { 2 - 9 } decile & $\Delta \mathrm{FTE}$ & $\Delta \mathrm{Y}$ & $\Delta \mathrm{FTE}$ & $\Delta \mathrm{Y}$ & $\Delta \mathrm{FTE}$ & $\Delta \mathrm{Y}$ & $\Delta \mathrm{FTE}$ & $\Delta \mathrm{Y}$ \\
\hline 1 & 0.06 & -162 & 0.06 & -163 & 0.07 & -496 & 0.07 & -498 \\
2 & 0.08 & -84 & 0.08 & -87 & 0.11 & -226 & 0.11 & -228 \\
3 & 0.12 & 16 & 0.13 & -1 & 0.17 & -48 & 0.17 & -56 \\
4 & 0.12 & 51 & 0.14 & 40 & 0.20 & 33 & 0.20 & 19 \\
5 & 0.13 & 57 & 0.16 & 66 & 0.23 & 54 & 0.23 & 54 \\
6 & 0.13 & 65 & 0.17 & 69 & 0.23 & 113 & 0.25 & 101 \\
7 & 0.05 & 34 & 0.07 & 44 & 0.09 & 47 & 0.11 & 40 \\
8 & 0.03 & 68 & 0.05 & 96 & 0.07 & 85 & 0.08 & 91 \\
9 & 0.04 & 74 & 0.06 & 117 & 0.08 & 203 & 0.12 & 250 \\
10 & 0.03 & 14 & 0.04 & 59 & 0.05 & 69 & 0.07 & 155 \\
\hline total & $\mathbf{0 . 8 0}$ & - & $\mathbf{0 . 9 7}$ & - & $\mathbf{1 . 3 0}$ & - & $\mathbf{1 . 4 0}$ & - \\
\hline \hline
\end{tabular}

Note: (a) $\triangle$ FTE stands for changes in FTE relative to overall aggregates as in 12 (b) $\Delta Y$ stands for changes in individual disposable incomes (in million euro) accounting for first and second round effects.

While individuals in the lower deciles are basically unaffected by the

\footnotetext{
${ }^{11}$ Of course, the regressive character of a tax deductible is at odds with the idea of a phase-out, however, the purpose of these simulations is to establish the feasibility of a compensating policy. If phase-outs really are to be implemented in this context, it would probably make sense to adopt tax credits instead of deductibles.

${ }^{12}$ Note that other combinations of thresholds and rates will also fulfill this criterion, however, the excercise only serves the purpose to show that compensation is feasible at relatively low cost.
} 
phase-outs, lower increases in disposable income (as compared to results in table 5) become visible in the middle ranges of the income distribution. In general, increases in disposable income are now lower for individuals in deciles 7-10, still, deciles 7 and 8 appear to bear the largest part of the burden. In terms of labor supply, however, the phase-out is not associated with adverse reactions. Due to the negative cross-wage elasticities of females in couples, households in higher-income deciles show slightly positive labor supply responses, particularly in the simulations with differential treatment of second earners.

Overall, these results thus confirm the conjectures noted at the end of section 4. While labor supply response is large in lower-middle deciles (i.e. at the extensive margin), lower responsiveness at the intensive margin implies that phasing-out deductibles at higher income is consistent with large positive employment effects (as discussed in this section). Although the proposed policy shifts imply decreases in disposable income for households in lower income deciles, the phase-out thus yields extra revenues which might be used to compensate these households. In order to target these funds towards lower-income households, they could either be used to increase earmarked subsidies for education or child care in these households or serve to increase child-related social transfers in general.

\section{Conclusion}

This chapter develops a structural discrete choice labor supply model for Austria based on the static microsimulation model ITABENA and the EUSILC datasets 2004-2010. We present static uncompensated own and cross wage elasticities at the intensive and extensive margins, as well as for different household types and income quantiles. We use the structural estimates to evaluate a recent family policy reform in Austria, and illustrate the full employment potential of small and large scale policy shifts towards stronger work incentives for families.

Our analysis of a family policy reform (in 2009) shows that tax deductibles for children and child care costs both had positive labor supply effects, while increases in universal child transfers had almost no impact. Although the overall volume of the reform remains modest, our simulations imply that around $10 \%$ of the first round increase in government expenditures can be made up through increases in tax revenues due to labor supply reactions. 
To further explore the employment potential of these new policy instruments, we increase the tax deductibles at the expense of a corresponding decrease in universal child transfers. The resulting policy simulations thus correspond to revenue-neutral shifts in government expenditures ranging up to 3.8 billion euro. In terms of overall employment effects these policy shifts yield increases of up to $1.31 \%$ of total aggregated full-time equivalents in Austria. As expected, male individuals show the lowest labor supply response, while males in couples as well as single females react somewhat stronger. By far the largest proportion of the total labor supply response is driven by females in couples who are shown to increase full-time equivalents by 2 to $3.9 \%$ of their total depending on the scale of the policy shift.

Furthermore, our results show that increasing the tax deductibles for second earners has the potential to unlock additional full-time equivalents, since such policies create positive jointness between spousal earnings', thus strengthening the link between working hours of second earners and disposable household income (Immervoll et al., 2009).

Although universal child transfers are, in general, associated with higher fertility, adverse effects on female labor supply are likely to manifest themselves in the short and, especially, the long-term perspective (Brewer et al. 2008; Del Boca and Sauer, 2009). Tax deductions, on the other hand, foster stronger labor market integration of women over the life-cycle, in particular when combined with subsidization of childcare costs and favourable employment legislation (Bargain and Orsini, 2006). Therefore, a policy shift from universal child transfers to child tax deductibles is unlikely to have negative effects on fertility in the long-term.

While our analysis reveals a large employment potential associated with shifts from universal transfers to tax deductibles, such a policy has highly regressive effects with regard to the distribution of disposable income. Since households in lower deciles have more children on average and tax deductibles reduce over-proportionally the tax liabilities of high-income households, first round effects of the proposed policy shifts imply that lower deciles lose in terms of disposable income. However, these effects are mitigated through labor supply responses which are much stronger in the lower-middle deciles.

Based on these results, we show that phasing-out the tax deductible at higher income allows, in principle, for the compensation of lower-income households without jeopardizing positive employment effects. Overall, these results thus imply that policy shifts towards stronger work incentives for families can in fact be achieved without making any individual worse off in 
monetary terms. 


\section{References}

Bargain, O. and Orsini, K. (2006). In-work policies in europe: Killing two birds with one stone? Labour Economics, 13:667-697.

Bargain, O., Orsini, K., and Peichl, A. (2011). Labor supply elasticities in europe and the us. IZA Discussion Papers 5820, Institute for the Study of Labor (IZA).

Bloemen, H. (2010). Income taxation in an empirical collective household labour supply model with discrete hours. IZA Discussion Paper, -(4697):160 .

Blundell, R., Duncan, A., McCrae, J., and Meghir, C. (2000). The labour market impact of the working families' tax credit. Fiscal Studies, 21(1):75103.

Blundell, R., Duncan, A., and Meghir, C. (1998). Estimating labor supply responses using tax reforms. Econometrica, 66(4):827-862.

Blundell, R. and MaCurdy, T. (1999). Labor supply: A review of alternative approaches. In Ashenfelter, O. and Card, D., editors, Handbook of Labor Economics, volume 3A, chapter 27, pages 1559 - 1695. Elsevier Science.

Brewer, M., Duncan, A., Shepard, A., and Suarez, M. (2006). Did working families' tax credit work? the impact of in-work support on labour supply in great britain. Labour Economics, 13:699-720.

Brewer, M., Ratcliffe, A., and Smith, S. (2008). Does welfare reform affect fertility? evidence from the uk. IFS Working Papers, 1:1-43.

Chemin, M. and Wasmer, E. (2011). Ex-ante and ex-post evaluation of the 1989 french welfare reform using a natural experiment : the 1908 social laws in alsace-moselle. Science Po, Departement of Economic Working Paper, 1:1-44.

Chiappori, P.-A. (1992). Collective labor supply and welfare. Journal of Political Economy, 100:437-467.

Chiappori, P.-A. and Donni, O. (2009). Non-unitary models of household behavior: A survey of the literature. IZA Discussion Papers 4603, Institute for the Study of Labor (IZA). 
Creedy, J. and Duncan, A. (2002). Behavioural mircosimulation with labour supply responses. Journal of Economic Surveys, 16:1-40.

Dearing, H., Hofer, H., Lietz, C., Winter-Ebmer, R., and Wrohlich, K. (2007). Why are mothers working longer hours in austria than in germany? a comparative microsimulation analysis. Fiscal Studies, 28(4):463-495.

Del Boca, D. and Sauer, R. (2009). Life cycle employment and fertility across institutional environments. European Economic Review, 53:274-292.

Diamond, P. and Saez, E. (2011). The case for a progressive tax: From basic research to policy recommendations. Journal of Economic Perspectives, 25(4):165-90.

Donni, O. (2007). Collective female labour supply: theory and application. Economic Journal, 117(516):94-119.

Donni, O. and Moreau, N. (2007). Collective labor supply: A single-equation model and some evidence from french data. Journal of Human Resources, $42(1)$.

Eissa, N. and Hoynes, H. W. (2004). Taxes and the labor market participation of married couples: the earned income tax credit. Journal of Public Economics, 88:1931-1958.

Garcia, J. and Suarez, M. J. (2003). Female labour supply and income taxation in spain: The importance of behavioural assumptions and unobserved heterogeneity specification. Hacienda Publica Espanola, 164(1):9-27.

Hansen, J. and Liu, X. (2011). Estimating labor supply responses and welfare participation: Using a natural experiment to validate a structural labor supply model. IZA Discussion Paper Series, -:1-33.

Hofer, H., Koman, R., Schuh, A., and Felderer, B. (2003). Das SteuerTransfer-Modell ITABENA. Technical report, Institute for Advanved Studies.

Hotz, J., Mullin, C., and Scholz, J. (2006). Examining the effect of the earned income tax credit on the labor market participation of families on welfare. NBER Working Paper Series, 11968:1-57. 
Hotz, V. J. and Scholz, J. K. (2003). The Earned Income Tax Credit, volume Means Tested Transfer Programs in the United States, chapter 3, pages 141-197. University of Chicago Press.

Hoynes, H. W. (1996). Welfare transfers in two-parent families: Labor supply and welfare participation under afdc-up. Econometrica, 64(2):295-332.

Immervoll, H., Kleven, H. J., Kreiner, C. T., and Verdelin, N. (2009). An evaluation of the tax-transfer treatment of married couples in european countries. IZA Discussion Papers 3965, Institute for the Study of Labor (IZA).

Lutz, H. and Schratzenstaller, M. (2010). Moegliche ansaetze zur unterstuetzung von familien durch die oeffentlichen haushalte. WIFO Monatsberichte, 8:661-674.

Mankiw, N. G., Weinzierl, M., and Yagan, D. (2009). Optimal taxation in theory and practice. Journal of Economic Perspectives, 23(4):147-74.

Manoli, D., Weber, A., Guren, A., and Chetty, R. (2011). Does indivisible labor explain the difference between micro and macro elasticities? a metaanalysis of extensive margin elasticities. 2011 Meeting Papers 73, Society for Economic Dynamics.

Meghir, C. and Phillips, D. (2008). Labour supply and taxes. The Institute for Fiscal Studies, WP 08/04.

Meyer, B. D. and Rosenbaum, D. T. (2001). Welfare, the earned income tax credit, and the labor supply of single mothers. Quaterly Journal of Economics, 116(3):1063-1114.

OECD (2011). Doing Better for Families. OECD Publishing.

Orsini, K. (2006). Tax-benefits reforms and the labor market: evidence from belgium and other eu countries. Center for Economic Studies - Discussion papers ces0606, Katholieke Universiteit Leuven, Centrum voor Economische Studien.

Peichl, A., Schneider, H., and Siegloch, S. (2010). Documentation IZAMOD: The IZA Policy Simulation Model. IZA Discussion Paper Series, -:1-30. 
Steiner, V. and Wakolbinger, F. (2009). The Austrian Tax Transfer Model ATTM: Version 1.0. Technical report, Gesellschaft fuer Angewandte Wirtschaftsforschung mbH.

Steiner, V. and Wrohlich, K. (2004). Household taxation, income splitting and labor supply incentives: A microsimulation study for germany. Discussion Papers of DIW Berlin 421, DIW Berlin, German Institute for Economic Research.

Train, K. E. (2009). Discrete Choice Methods with Simulation. Cambridge University Press.

Van Soest, A. (1995). Structural models of family labor supply. Journal of Human Resources, 30:63-88.

Wernhart, G. and Winter-Ebmer, R. (2012). Do austrian men and women become more equal? at least in terms of labour supply! Empirica, 39(1):4564 .

Wrohlich, K. (2006). Labor supply and child care choices in a rationed child care market. IZA Discussion Paper Series, 2053:1-31. 